\title{
Can Instant Messaging Platform QQ Help Solving the Deficiency of EFL Learners' Critical Literacy in China?
}

\author{
Quanyou Ruan \\ School of Foreign Languages \\ Zhongnan University of Economics and Law \\ Wuhan, P.R. China \\ neilruan@163.com
}

\begin{abstract}
This study is designed as a qualitative case study to explore the application of the instant messaging platform QQ in an EFL class in China, aiming at promoting learners' critical literacy. After analyzing the data collected in observation, surveys and interviews, this study finds that QQ can serve for building a learning environment that encourages deep content-based discussions in critical literacy activities. The author also presents some suggestions for future educational research and practice, as well as the implications for software engineering.
\end{abstract}

Keywords - instant messaging platform, QQ, critical literacy, implications for Software engineering

\section{INTRODUCTION}

In China, the pursuit of Chinese Dream demonstrates an urgent need for the growing confidence and awareness of the importance of identity building individually and nationally. Particularly, in language education, as language carries certain social, cultural information, and serves as a cultural capital, thus plays a tremendously significant role in the long-term national development strategy. Meanwhile, in Chinese EFL education, the heated discussions on language learners' deficiency of critical literacy in literature[1-3] imply a general trend that current foreign language teaching and learning should be re-examined reflectively with an engagement of critical thinking, or critical literacy, rather than stay still and remain only to be an instrumental need for economic development which is established and rooted in traditional approach. Accordingly, integrating critical literacy and critical pedagogy in language education has aroused much attention in the latest few years.

Despite a group of researchers' pioneering works in studies such as critical thinking skills test and its applications in English education[4, 5], policy-making [2] and proposed model for critical literacy development [1], there are still much work to be further explored. Fortunately, previous study has revealed that two key factors should be seriously considered in future work [1, 3]: 1) learning environment that supports dialogical discussion; 2) topics that encourage in-depth content-based communication. Therefore, this study aims to examine firstly how to use Tencent QQ - the most famous instant messaging platform in China - in EFL language teaching and learning in order to improve students' critical literacy; and then discuss the findings in a case study from the above-mentioned two key factors. Finally, this paper will propose implications for future study.

\section{RELATED WORK}

According to the recent official report [6], Tencent QQ is one of the most famous and popular Internet service portals for instant messaging in China. Statistics show that in the first quarter of 2013, the monthly active user accounts of Instant Messaging are 825.4 million and the peak simultaneous online user accounts of Instant Messaging are 173.0 million. Although it is not designed particularly for educational purpose, it is one of the most frequently-used platforms on internet and the primary mobile communication tool among university students. Thus, in educational research, it has aroused much attention in different projects such as using QQ to study the emotional indifference between teachers and students in higher education[7], to construct collaborative learning community [8], to enhance academic English writing[9] and translation[10]. However, the application of this popular instant communication tool in solving the deficiency of critical literacy in a Chinese context is rare, thus initiates the research motivation of this study.

\section{RESEARCH QUESTIONS}

In order to meet the aims of this study, this project is going to answer the following questions:

a) What will Tencent QQ serve for building a learning environment good for critical literacy?

b) Will Tencent QQ help to encourage deep contentbased discussion in critical literacy activities, why?

c) What will the future EFL education and software engineering benefit from this project?

\section{Methodology}

A qualitative case study was conducted to answer the research questions in a second-year EFL class from March to July, 2011 in a university located in Wuhan, Hubei province, China.

\section{A. Participants and context}

48 university students (39 females and 9 males) participated in this project. The students were second-year English majors at Zhongnan University of Economics and Law. The course involved in the current study is Basic 
English. It can represent the learning situation of students since 1) it is a compulsory course for English majors in universities or colleges in Chinese higher education ranging from Comprehensive universities, Foreign languages institutes, to private institutions; 2) It emphasizes four basic skills (listening, speaking, reading and writing), thus can respond to the main argument of the deficiency of critical literacy, namely, focusing too much on language skills rather than empowerment of the students in critical activities.

\section{B. Integration of Tencent $Q Q$ in online communication}

Since QQ supports comprehensive online communication functions, including text messaging, video/voice chat, QQ group interaction, web-blog, email service, as well as online/offline file-sharing and filetransmission. Moreover, It can be used in our daily life in cross-platform communication between PC and Smart phone, Tablet PC and other wireless terminals.

Thus, it has been employed in designing the communication activities in this cause subject under the two assumptions: 1) This instant messenger can bridge the gap between students' classroom learning activity and their life experience; 2) it can also encourage content-based deep learning with regard to their critical literacy development.

In order to build an online learning community, at the beginning of the semester, a QQ group was registered, and all the students as well as the teacher were invited to join as group members. This study then divide students into ten small groups according to their own personal tastes, including Chinese business, world business, sports, entertainment, education, science and technology, world affairs, China affairs, travel and culture, and life and health. Tasks were based on the reading materials they chose themselves from their daily life (newspaper, TV programs, everyday talks etc.), for examples, introducing "What's new" in their own group by providing other students an interesting news story on a regular basis with the information and proper background, raising some questions in QQ applications, and generating related discussions to exchange comments or understandings on a specific issue.

\section{Data resources and Data analysis}

By using qualitative approach, this study collects data through QQ chat box, forum discussions and classroom observation, surveys and interviews for trustworthiness and then transcribes them into transcription texts for further analysis. This study finally tries to find the changes of students' learning with regard to the two key factors that affect critical literacy development based on the data selected from two stages(early stage and final stage).

\section{FINDINGS AND DISCUSSION}

This study lasted for 18 weeks in one semester, and Data analysis is based on the forum discussion topics, frequency of students' participation in forum discussion, threads of forum discussion, students' classroom performances before (Stage 1) and after (Stage 2) the pedagogical intervention, pre- and post- surveys about the application of QQ in their everyday life in two stages, and several semi-structured face-to-face interviews for further understanding of their responses in surveys. In response to the research questions, this section discusses the findings from the following three aspects:

\section{A. The application of QQ messenger in their life}

Students use QQ very often, and obviously it's the primary online communication tool among them. This can be found both in surveys and interviews in Stage 1 and Stage 2. In Stage 1, QQ has not been required in discussion activities. The survey results show that all students (100\%) in this study own at least one QQ account, they log onto the platform at least once nearly everyday from personal computer (PC). And 57\% students also use it via the applications in smart phones, this number rises to $63 \%$ in Stage 2.

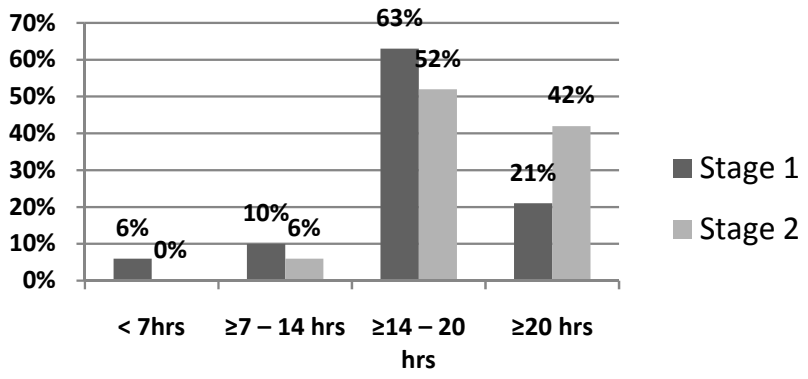

Figure 1: Weekly Online Hours Staying in QQ Platform in Stage 1 and Stage 2

For the question about how long the student may stay online via QQ per week, Figure 1 tells us that in Stage 2, more students have been involved in QQ activities. Among those " $\geq 14-20 \mathrm{hrs"}$ " and "more than $20 \mathrm{hrs"} \mathrm{per} \mathrm{week,} \mathrm{it}$ increases from $84 \%$ to $94 \%$, indicating that the intense engagement of this pedagogical design though the change is not significant. More findings can be discovered in questions on what do they do on QQ platform later.

In Stage 1, according to the survey and the follow-up interviews, they mainly use this platform to make new friends or stay in touch with old friends or families, and QQ chat or Group chat serves sometimes as only a notice board, or the lost-and-found etc. While in Stage 2, besides all the functions in Stage 1, the major part of its implication is for sharing news stories, raising questions, encouraging discussions and exchanging opinions in English. Group realtime chatting and QQ forum discussion produce a large number of discussion notes and threads (as we can see in Table 1).

\section{B. Participation of $Q Q$ discussion}

The statistics of Students' participation in discussion on QQ platform indicate that a) They read in a wide range of topics derived from their life and personal interests. In Table 1, it is very clear that there are about ten different topics or areas the students can read and share information within or cross groups. During the 
whole semester, the whole class read 1949 pieces of English news items or story items, 41 in average per student. If comparing with the traditional class where their readings are only based on printed textbooks, normally cover 20 passages in 10 units (in other words, 48 students learn 20 texts within 18

TABLE 1: QQ FORUM DISCUSSION

\begin{tabular}{|l|r|r|}
\hline \multicolumn{1}{|c|}{ Group Themes } & \multicolumn{1}{c|}{ Items } & \multicolumn{1}{c|}{ Threads } \\
\hline Chinese business & 132 & 528 \\
\hline World business & 196 & 657 \\
\hline Sports & 181 & 703 \\
\hline Entertainment & 114 & 684 \\
\hline Education & 235 & 589 \\
\hline Sci \& Tech & 242 & 626 \\
\hline World affairs & 262 & 586 \\
\hline China affairs & 178 & 534 \\
\hline Travel and culture & 138 & 690 \\
\hline Life and health & 177 & 708 \\
\hline Others Total & 94 & 282 \\
\hline \multicolumn{2}{r|}{1949} & 6587 \\
\hline
\end{tabular}

weeks), 1949 is far beyond the number 20. Moreover, their discussions based on these content-based materials generate nearly 7,000 threads. While in traditional classroom, the learning production is much less than the rich text exchanges and ideas sharing on QQ platform.

\section{Changes in learning from Stage 1 to Stage 2}

In Stage 1, the first interview was arranged at the first week of the semester in order to understand the English learning experience of the students, the results show that their previous learning is mainly classroom-based and teacher-centred, and print-focused. Classroom is the major place that teacher and students can communicate, the classroom activities and discussions are usually started by the teacher based on the content from the printed textbook. Although sometimes the teacher does encourage students' autonomous motivation in classroom small-group discussions, or in debating activities, the limitation of the time-and-space in a small room cannot engage all individual students' participation, thus there are always marginalized students keeping in quiet or being ignored. Furthermore, print-focused reading focused on vocabulary, grammar rules and has always been regarded as something boring and far away from their lived experience, thus as an excuse to their silence in class.

In Stage 2, by extending some readings and discussion activities onto the QQ platform, the results of students' interview demonstrate a tremendous change in their learning (Table 2). These changes can be discussed from the following perspectives:

First of all, the students are aware that they are now reading more materials than ever before. It can be proved from examples like "there are many opportunities for me to read and use English(S1)", "read a lot (S2)", "routinely (S3)", "can get access to more information (S5)", and "I have been reading more news information than last year (S10)",
Second, the students enjoy expressing and sharing ideas with others, such as "expressing myself in English is now part of my life (S1)", "I am not afraid of speaking (S2)", "I can speak more than ever before (S4)", "(benefits from)...participating a variety of discussions (S6)", "make me feel the fun of discussing with other people (S8)". And the change is great when they say " for the first time... (S1)" and "I am now... (S4, S5, S9,S12)".

TABLE 2: SAMPLES OF STUDENTS' INTERVIEWS

\begin{tabular}{|c|c|}
\hline No. & Students' interview samples \\
\hline S1. & $\begin{array}{l}\text { In my English learning, for the first time I find that there are } \\
\text { many opportunities for me to read and use English, and } \\
\text { expressing myself in English is now part of my life. }\end{array}$ \\
\hline S2. & $\begin{array}{l}\text { Since I read a lot and always discuss and exchange opinions } \\
\text { on QQ platform, I am not afraid of speaking in class any more. } \\
\text { Moreover, this approach teaches me to observe from different } \\
\text { perspectives and provides me with a new insight into things, } \\
\text { which I will not learn from the textbooks. }\end{array}$ \\
\hline S3. & $\begin{array}{l}\text { I have learned the way of critical thinking. Knowing things } \\
\text { from daily English news routinely have enhanced my } \\
\text { understanding of the textbook. }\end{array}$ \\
\hline S4. & $\begin{array}{l}\text { When answering questions, I am now more likely to be in a } \\
\text { dialectical way of thinking, and can speak more than ever } \\
\text { before. }\end{array}$ \\
\hline S5. & $\begin{array}{l}\text { On account of the fact that I can get access to more } \\
\text { information and communication, I am now concerning more } \\
\text { about thought and content rather than the expressions only } \\
\text { carry superficial understandings in my previous learning. }\end{array}$ \\
\hline S6. & $\begin{array}{l}\text { What I benefit most is from reading news items that I like and } \\
\text { participating a variety of discussions. }\end{array}$ \\
\hline S7. & $\begin{array}{l}\text { Reading and discussing English news information can be good } \\
\text { for improving language performance and overall English } \\
\text { language ability, thus is worth popularizing. }\end{array}$ \\
\hline S8. & $\begin{array}{l}\text { The small group discussion in QQ groups make me feel the fun } \\
\text { of discussing with other people, instead of the quiet moment } \\
\text { due to shyness in my previous learning. }\end{array}$ \\
\hline S9. & $\begin{array}{l}\text { When I express myself in English, I am now paying more } \\
\text { attention to my viewpoint on something, rather than just } \\
\text { superficial description. }\end{array}$ \\
\hline S10. & $\begin{array}{l}\text { I have learned many new ideas since I have been reading } \\
\text { more news information than last year. }\end{array}$ \\
\hline S11. & $\begin{array}{l}\text { It is a unique learning method that encourages the build-up of } \\
\text { knowledge and integrates English learning into our daily } \\
\text { experiences. }\end{array}$ \\
\hline S12. & $\begin{array}{l}\text { In this class, I really appreciate that the teacher would not } \\
\text { repeat what the books say, rather he encourages us to care } \\
\text { more about the daily life, society and the outside world. This } \\
\text { approach makes English learning more relaxed than ever } \\
\text { before, and I can also learn things out of the books. Most } \\
\text { interestingly, I can now say goodbye to the old time when I used } \\
\text { to waste time in chatting with QQ messenger. I am not feeling } \\
\text { any guilty of using it now, for the discussion is really } \\
\text { geilivable. }\end{array}$ \\
\hline
\end{tabular}
(S: student)

Thirdly, The students treasure the connection of English learning and their life experience now. For instances, "part of my life (S1)", "which I will not learn from the textbooks (S2)", "integrates English learning into our daily experiences (S11)", "care more about the daily life, society and the outside world (S12)".

Fourth, the students are now concerning more about content of their language learning. Student 5 says "I am now concerning more about thought and content". Similarly 
it can also be found in S9 about her growing attention to viewpoints rather than superficial description.

Next, the students agree that QQ - as just an instant messenger in their life before - is now a powerful learning environment for them to exchange ideas in language learning. Such as what S2 says, the activities on QQ platform change her to a girl who can express ideas bravely now and S8 changes from a shy girl to a person who enjoys the fun in QQ discussions. When S12 expresses his viewpoints, he mentions that QQ used to waste him a lot time in chatting, but now "I am not feeling any guilty of using it now, for the discussion is really geilivable (S12)".

Finally, the students also appreciate the awareness of critical engagement in English learning which is different from their previous experience. For examples, "observe from different perspectives... a new insight into things (S2)", "the way of critical thinking (S3), "dialectical way of thinking (S4)", "I am now concerning more about thought and content (S5)", "paying more attention to my viewpoint on something (S9)". It is very impressive when the students say that this teaching and learning approach "is worth popularizing (S7)".

\section{CONCLUSION}

After the discussion on findings discovered from all the collected data, it is then imperative to go back to the research questions, summarize and conclude the project.

RQ1: What will Tencent QQ serve for building a learning environment good for critical literacy?

From the data and discussion, we can find that Tencent QQ serves just as an instant communication tool for people in life, but since it provides us an important digital context, situates in our everyday life, then holds great potential to enhance the current limited discussion section in classroom. With regard to the deficiency of EFL learners 'critical literacy, QQ platform can be the bridge between language classroom and students' life experience, and help to build the communities of practice[11], thus encourage them conveniently discuss in learning and experiencing. According to Wenger [11], the primary focus of Communities of Practices is learning as social participation. Participation "shapes not only what we do, but also who we are and how we interpret what we do" [11]. Obviously, QQ platform can serve for building a learning environment good for critical literacy.

RQ2: Will Tencent QQ help to encourage deep contentbased discussion in critical literacy activities, why?

The answer is definitely yes. This can be proved from our discussion on how students change their role from just an ordinary instant messenger user to a information-seeker, question-raiser, idea-promoter, evaluator, collaborator, peer learner, and more importantly, a critical thinker and and decision maker. It can also be indicated from the content of communication on QQ platform, the frequency of their QQ forum discussion and the threads of their replies and dialogues online. In addition, the students' responses to interview questions can also tell us that this pedagogy can empower the students' inner side, and make them the creative and effective emancipatory human being.
RQ3: What will the future EFL education and software engineering benefit from this project?

First, this study shows that when digital text representation permeates our life and becomes a major part of our life, the limitation of traditional classroom-based learning environment is clear and the teacher-centred pedagogy and print-focused learning material cannot serve for the multiple dimensions of literacy education. Thus, blending new elements from both pedagogical concerns and technological applications in education is significant and urgent for both teachers, students, and educational administrators.

Next, QQ implication in this study witnesses the potential of software engineering for development of students' critical literacy among all those new literacies in this digital age, therefore, more expectations from the education practices will be helpful for software programmers. As for this study, the future design of QQ should consider the huge market share if it can provide special plug-ins for educational end-users, or in other words, combines technology with pedagogy together in future programming. For example, it can develop applications about the evaluation of students' participation, assignments, knowledge-building activities, knowledge management in educational settings, questionnaire or quiz resources, online QQ workshops, QQ presentations and so on.

\section{ACKNOWLEDGEMENT}

This research was supported by the 11th Five-Year National Education Scientific Planning Research Funds of China (Grant NO. GPA105031) and the Humanities and Social Science Research Funds of Ministry of Education of China (Grant NO. 10YJC740088).

\section{REFERENCES}

[1] Ruan, Q.: 'Constructing the Conceptual Framework for Developing College English Majors' Critical Literacy', Foreign Language World (Wai Yu Jie), 2012, (1), pp. 19-26

[2] Huang, Y.: 'A complete reform in course design for English majors: on deficiency of Critical Thinking skills', Foreign Language World (Wai Yu Jie), 2010, 132, (1), pp. 11-16

[3] Sun, Y.: 'Toward a Critical Thinking-oriented Curriculum for English Majors', Foreign Languages in China, 2011, 8, (3), pp. 49-58

[4] Wen, Q., Wang, J., Zhao, C., Liu, Y., and Wang, H.: 'Developing a conceptual framework for assessing Chinese university students critical thinking skills', Foreign Language World (Wai Yu Jie), 2009, 130, (1), pp. 37-43

[5] Wen, Q., Wang, J., Zhao, C., Liu, Y., and Wang, H.: 'Study of the Reliability of Critical Thinking Disposition Inventory for Chinese College Students', Computer-assisted Foreign Language Education in China, 2011, 142, (6), pp. 19-23

[6] http://www.tencent.com/enus/content/at/2013/attachments/20130515. pdf

[7] Xu, J.: 'The Communication based on QQ between Teachers and Students in Colleges and Universities', Education and Teaching Research, 2009, 23, (4), pp. 13-16

[8] Zhang, H., Li, R., and Li, M.: 'Social Network Analysis of QQ Virtual Learning Community', Modern Educational Technology, $2009,19,(12)$, pp. $80-83,+125$ 
[9] Liu, B.: 'Application of English Writing Training Mode based on QQ Network Platform in Vocational School', Education and Teaching Research, 2010, 24, (4), pp. 102-104
[10] Dai, J.: 'Study on the Construction and Application of QQ-based Interactive After-class Translation Teaching Model', Computerassisted Foreign Language Education in China, 2011, (2), pp. 61-66

[11] Wenger, E.: 'Communities of practice : learning, meaning, and identity' (Cambridge University Press, 1998.1998 ) 